\title{
STUDI PERKUATAN TANAH DASAR DI BAWAH EMBANKMENT MENGGUNAKAN METODE KOMBINASI PRELOADING DAN PVD
}

\author{
(Studi Kasus: Pembangunan Jalan Tol Pasuruan Probolinggo Seksi 2 Sta 15+500)
}

Dedy Dana Fahrur Rizal ${ }^{1}$, Arief Alihudin², Adhitya Surya Manggala ${ }^{3}$

\author{
Program Studi Teknik Sipil, Fakultas Teknik, Universitas Muhammadiyah Jember ${ }^{1,2,3}$ \\ J1. Karimata 49, Jember 68121, Indonesia \\ email: dedydanafr@gmail.com
}

\begin{abstract}
Stability of the subgrade is important as a support for the construction on it, especially on the paspro toll road, which is planned to be built on a pile with a relatively high elevation of 0 meters to 9 meters at STA $15+500$ elv heaps of 8.5 meters. In addition, the investigation of the land at the location shows that the subgrade in the Paspro toll road plan is soft clay soil up to a depth of 10.36 meters so that it needs repairs to the subgrade. In the analysis of the subgrade there was a soil drop of 0.8 meters if it was burdened by a pile and was only able to carry a 1.5 meter high embankment. The method of soil improvement used is the method of preloading the surcharge system and the acceleration of compression time using PVD. The results of PVD installation with a triangle and square pattern with a distance of 1 meter can increase the degree of consolidation by $98 \%$ within 6 weeks which impacts on the carrying capacity of the subgrade to be able to withstand the load of 9 meters high embankment.
\end{abstract}

Keywords: Stability of embankment, settlement, carrying capacity, preloading, PVD.

\begin{abstract}
Abstrak
Stabilitas tanah dasar merupakan halpenting sebagai penopang konstruksi di atasnya khususnya pada tol paspro yang rencananya akan dibangun di atas timbunan dengan elevasi yg relatif tinggi yaitu 0 meter s/d 9 meter pada STA 15+500 elv timbunan 8.5 meter. Selain itu penyelidikan tanah di lokasi tersebut menunjukan bahwa tanah dasar pada rencana jalan tol Paspro merupakan tanah lempung lunak hingga kedalaman 10.36 meter sehingga diperlukan perbaikan tanah dasar. Dalam analisa tanah dasar terjadi penurunan tanah sebesar 0.8 meter jika di bebani oleh timbunan dan hanya mampu memikul beban timbunan setinggi 1.5 meter. Metode perbaikan tanah yg digunakan adalah metode preloading sistem surcharge dan percepatan waktu pemampatan menggunakan PVD. Hasil pemasangan PVD dengan pola segitiga dan bujur sangkar dengan jarak 1 meter mampu menaikan derajat konsolidasi sebesar 98\% dalam waktu 6 minggu yang berimbas pada daya dukung tanah dasar menjadi mampu menahan beban timbunan setinggi 9 meter.
\end{abstract}

Kata kunci: Stabilitas embankment, Settlement, Daya dukung, Preloading, PVD.

\section{PENDAHULUAN}

\section{Latar Belakang}

Laju kegiatan ekonomi nasional setiap tahun mengalami peningkatan, sebesar $5,01 \%$ pada kuartal tahun 2017 (BPS, 2017). Pertumbuhan tersebut tidak terlepas dari lancarnya peranan transportasi sebagai media pengirim barang/jasa. Seiring peningkatan laju ekonomi, peningkatan laju transportasi juga pasti akan terjadi. Peningkatan laju transportasi ini ditandai dengan adanya kemacetan jalan sehingga diperlukan sebuah jalan baru dalam upaya memperlancar mobilitas arus barang dan manusia. Pembangunan sebuah jalan tol adalah salah satu solusi yang dapat meningkatkan pertumbuhan ekonomi suatu daerah serta dapat membantu mobilitas antara barang dan manusia lebih cepat. Jalan Tol Pasuruan - Probolinggo (Paspro) merupakan salah satu perencanaan dari ruas Jalan Trans Jawa, yang menghubungkan Kota Pasuruan dan Kabupaten Probolinggo. Pembanguan jalan tol ini di bagi menjadi 3 
seksi yakni seksi 1 (sta $00+000-13+500$ ), seksi 2 (sta $13+500-20+400)$, seksi 3 (sta $20+400-31+300)$.

Jalan tol ini akan dibangun di atas timbunan dengan elevasi yg relatif tinggi yaitu 0 meter s/d 9 meter. Pada seksi 2 khususnya di sta $15+500$ timbunan setinggi 8.5 meter di bangun diatas tanah rawa, selain itu penyelidikan tanah menunjukan bahwa tanah dasar pada lokasi tersebut merupakan tanah hitam yang memiliki karakteristik lunak yang saat musim hujan dan pada saat musim kering mengeras (silty clay) hingga kedalaman 4.48 meter, diperlukan perbaikan tanah dasar yang tepat dan cepat agar pembangunan jalan tol tersebut bisa sesuai dengan rencana karena untuk perbaikan tanah yang di lakukan saat ini dengan menggunakan metode Geotextile dan Sub draine memerlukan waktu yang relatif lama untuk mencapai kemampatan yang maksimum yakni di perlukan waktu selama 6 bulan agar tanah dasar tersebut benar - benar stabil dan dapat menerima beban yang besar.

Dari masalah tersebut penulis mencoba merencanakan perbaikan tanah yang lebih cepat, dengan menggunakan metode preloading yang di kombinasikan dengan PVD (pabricated vertical draine) yang di harapkan dapat mempercepat proses pemampatan tanah sehingga efisiean dalam waktu pengerjaan.

\section{Rumusan Masalah}

Berdasarkan latar belakang diatas, maka pada rumusan masalah pada Tugas Akhir ini adalah sebagai berikut:

1. Bagaimana kondisi geoteknis lapisan tanah dasar STA 15+500?

2. Bagaimana tinggi timbunan perencanaan STA $15+500$ ?

3. Bagaimana cara perencanaan PVD untuk jangka waktu tertentu?

4. Bagaimana daya dukung timbunan menggunakan metode preloading?

\section{Tujuan}

1. Mengetahui dan memperhitungkan kondisi geoteknis tanah dasar STA $15+500$

2. Merencanakan perhitungan tinggi timbunan STA $15+500$
3. Mengetahui pola pemasangan dan jarak antar vertical draine

4. Mengetahui daya dukung timbunan dengan metode preloading

\section{Maksud}

Adapun maksud penulisan tugas akhir ini adalah menaganalisa stabilitas timbunan dengan kombinasi metode preloading dan PVD, mengetahui nilai faktor keamanan dan dapat memberikan informasi kepada para pembaca

\section{Batasan Masalah}

1. Tidak menghitung metode pelaksanaan

2. Tidak menghitung RAB

\section{Sistematika Penulisan}

Secara garis besar, sistematika penulisan tugas akhir ini adalah:

- Bab I Pendahuluan, menjelaskan tentang latar belakang, rumusan masalah, batasan masalah, tujuan, manfat dan sistematika penulisan laporan.

- Bab II Dasar teori, meliputi teori sebagai landasan penyusunan tugas akhir.

- Bab III Metodologi, merupakan prosedur kerja yang digunakan dalam tugas akhir.

- Bab IV, Analisa Data dan Pembahasan, merupakan suatu tahap pengolahan dan analisa data yang didapatkan selama tugas akhir.

- Bab V Penutup, merupakan bagian penutup tugas akhir yang meliputi Kesimpulan dan Saran.

\section{Tinjauan Pustaka}

Pengertian Dan Jenis Tanah

Tanah merupakan kumpulan - kumpulan dari bagian -bagian yang padat dan tidak terikat antara satu dengan yang lain (diantaranya mungkin material organik) rongga - rongga diantara material tersebut berisi udara dan air. (Verhoef, 1994)

Tanah terdiri atas agregat dan mineral mineral yang padat yang tidak terikat secara kimia satu sama lain. Tanah bersifat heterogen yaitu dapat mempunyai sifat - sifat yang 
berbeda pada jarak yang berbeda disebabkan oleh faktor ukuran, bentuk komposisi kimia dari butiran, sehingga setiap tanah memiliki paremeter tanah yang berbeda-beda. Parameterparameter tanah dapat ditentukan berdasrkan uji laboratorium, uji lapangan maupun berdasarkan korelasi parametrik tanah. (Braja M. Das, 1990)

Kondisi geoteknik erat hubunganya dengan jenis tanah. Tanah dalam pengertian teknik secara umum dapat diartikan sebagai material yang terdiri dari agregat (butiran) mineramineral padat yang tidak tersementasi (terikat secara kimia) satu sama lainya dan dari bahan bahan organik yang telah melapuk (yang berpartikel padat) disertai dengan zat cair dan gas yang mengisi ruang-ruang kosong diantara partikel-partikel padat tersebut. Butiran-butiran mineral yang membentuk bagian padat dari tanah merupakan hasil dari pelapukan batuan. Ukuran setiap butiran padat tersebut sangat bervariasi dan sifat 7 fisik dari tanah bergantng pada faktor ukuran, bentuk, dn komposisi kimia butiran.

Secara garis besar karakteristik dari tanah dapat diuraikan sebagai berikut :

1. Pasir lepas

Suatu deposit pasir dengan kepadatan yang rendah. Beban bergetar cenderung akan memadatkan deposit ini, sehingga getaran akan dapat mengakibatkan penurunan yang tidak dpat ditoleransikan pada tanah jenis ini.

2. Tanah looses

Suatu deposit tanah yang relatif seragam, tanah lanau bawaan angin. Tanah ini memiliki permeabilitas vertikal yang relatif tinggi, tetapi permeabilitas horozontal yang relatif rendah. Tanah jenis ini akan menjadi sangat compressible apabila dalam keadaan jenuh.

3. Lempung terkonsolidasi normal (normally consolidated clay)

Tanah lempung yang tidak pernah menderita tekanan yang lebih besar daripada tekanan yang ada saat sekarang. Tanah ini cenderung compressible, memiliki daya dukung ultimit yang rendah dan permeabilitas yang juga rendah
4. Lempung terkonsolidasi lebih (over consolidated clay)

Tanah lempung yang pada masa silam pernah menderita beban yang lebih besar daripada beban yang ada sekarang ini. Lempung jenis ini cenderung akan memiliki daya 8 dukung ultimit yang lebih tinggi dan relatif tidak compressible

5. Bentonit

Lempung yang mempunyai plastisitas tinggi yang dihasilkan dari dekomposisi abu vulkanis. Tanah ini bersifat ekspansif yang akan mengembang cukup besar pada kondisi jenuh.

6. Gambut

Bahan organis setegah lapuk berserat atau suatu tanah yang mengandung bahan organis berserat dalam jumlah besar. Gambut mempunyai angka pori yang sangat tinggi dan juga sangat compressible.

\section{Besar Pemampatan Tanah}

Penurunan tanah pada umumnya disebabkan oleh pembebanan, dapat dibagi dua kelompok besar yaitu:

1. Penurunan segera (immediate settlement) yaitu penurunan yang diakibatkan oleh perubahan bentuk elastis tanah tanpa perubahan kadar air. Penurunan segera pada umumnya didasarkan pada penurunan yang diturunkan dari teori elastisitas. (Das, Braja M. 1991).

2. Penurunankonsolidasi (consolidation settlement) yaitu penurunan yang diakibatkan oleh perubahan volume tanah jenuh air akibat dari keluarnya air yang menempati pori-pori tanah.

Berdasarkan teori Terzaghi (1925) untuk perhitungan pemampatan pada tanah lempung adalah:

1. Untuk tanah terkonsoldasi normal (Normally Consolidated Soil)

$S_{c i}=\left[\frac{c_{c}}{1+e_{0}} \log \frac{p \prime_{0}+\Delta p}{p_{0}^{\prime}}\right] \times H_{i}$

2. Untuk tanah terkonsolidasi lebih (Over Consolidated Soil) 


$$
\begin{gathered}
\text { Jika } p_{0}^{\prime}+\Delta p<P^{\prime}{ }_{c} \text { maka } \\
S_{c i}=\left[\frac{C_{s}}{1+e_{0}} \log \frac{p \prime_{0}+\Delta p}{p_{0}}\right] \times H_{i} \\
S_{c i}=\left[\frac{C_{s}}{1+e_{0}} \log \frac{p_{c}^{\prime}}{p_{0}^{\prime}}+\frac{c_{c}}{1+e_{0}} \log \frac{p_{0}^{\prime}+\Delta p}{p_{c}^{\prime}}\right] \times H_{i}
\end{gathered}
$$

Dimana:

$\mathrm{Sc}_{\mathrm{i}}$ : pemampatan konsolidasi pada lapisan tanah yang ke-I yang ditinjau

$\mathrm{H}_{\mathrm{i}}$ : tebal lapisan tanah ke-i

$\mathrm{e}_{\mathrm{o}}$ : angka pori awal dari lapisan tanah ke-i

$\mathrm{C}_{\mathrm{c}}$ : indeks kompresi dari lapisan ke-i

$\mathrm{C}_{\mathrm{s}}$ : indeks mengembang dari lapisan ke-i

$\mathrm{P}_{\mathrm{o}}$ ': Tegangan Overburden efektif

$\mathrm{P}_{\mathrm{c}}$ ': Tegangan prakonsolidasi efektif

$\Delta \mathrm{p}$ : penambahan beban vertikal pada lapisan yang ditinjau akibat bebantimbunan dihitung dengan persamaan: $\Delta \mathrm{p}=\mathrm{I} \times \mathrm{q}$

\section{Waktu Konsolidasi}

Menurut Terzaghi dalam Das (1985), lama waktu konsolidasi (t) dapat dihitung dengan persamaan

$$
t=\frac{T_{v}\left(H_{d r}\right)^{2}}{C_{v}}
$$

Dimana:

Tv: faktor waktu, tergantung dari derajat konsolidasi U

$\mathrm{H}_{\mathrm{dr}}$ : tebal lapisan yang mengalami konsolidasi (panjang aliran yang harus ditempuh air pori)

$\mathrm{Cv}$ : koefisien konsolidasi untuk aliran air pori arah vertical

t: lama waktu untuk menyelesaikan konsolidasi (Mochtar, 2000)

Untuk menentukan derajat konsolidasi akibat aliran air pori secara vertikal, digunakan persamaan berikut:

Untuk Uv anatara $0 \%$ s/d $60 \%$

$\bar{U}_{v}=\left(2 \sqrt{\frac{T_{v}}{\pi}}\right) \times 100 \%$

Untuk Uv > 60\%

$\bar{U}_{v}=\left(100-10^{a}\right) \%$

Dimana:

$$
\begin{gathered}
a=\frac{1.781-T_{v}}{0.933} \\
T_{v}=\frac{t \times C_{v}}{H_{d r}{ }^{2}}
\end{gathered}
$$

\section{Tinggi Timbunan Awal ( $H$ initial)}

Untuk terjadinya pemampatan pada tanah dasar maka dilakukan pemberian beban berupa timbunan tanah (surcharge) atau disebut dengan preloading. Fungsinya sebagai beban untuk mempercepat pemampatanan, mengisi ruang yang diakibatkan oleh pemampatan dan meningkatkan daya dukung tanah di bawahnya. Setelah pemampatan tanah dasar terjadi, tinggi timbunan awal $\left(\mathrm{H}_{\mathrm{awal}}\right)$ yang direncanakan akan sesuai dengan dengan tinggi timbunan yang direncanakan $\left(\mathrm{H}_{\mathrm{akhir}}\right)$. Penentuan tinggi awal pada saat pelaksanaan (dengan memperhatikan penurunan), dapat hitung dengan persamaan berikut:

$$
\begin{aligned}
& q_{\text {akhir }}=q=\left(H_{\text {awal }}-S_{c}\right) \gamma_{\text {timb }}+S_{c}\left(\gamma_{\text {sat tim }}\right. \\
& \left.-\gamma_{w}\right) \\
& q=H_{\text {awal }} \times \gamma_{\text {timb }}-S_{c} \times \gamma_{\text {timb }}+S_{c} \times \gamma_{\text {timb }}^{\prime} \\
& q=H_{\text {awal }} \times \gamma_{\text {sat }}-S_{c}\left(\gamma_{\text {timb }}-\gamma^{\prime}\right) \\
& \text { Jadi, } \quad H_{\text {awal }-i}=\frac{q_{i}+S_{c i}\left(\gamma_{\text {timb }}-\gamma_{\text {timb }}^{\prime}\right)}{\gamma_{\text {sot }}} \\
& H_{\text {akhir-i }}=H_{\text {awal-i }}-S_{c i}
\end{aligned}
$$

\section{Preloading Tanah Timbunan}

Pemberian timbunan dengan system bertahap

Dengan beban bertahap, waktu yang dibutuhkan untuk mencapai ketinggian timbunan rencana cukup lama dan tergantung pada peningkatan daya dukung tanah dasarnya. Penambahan beban setiap lapisan beban preloading mengacu pada ketinggian yang masih mampu dipikul $\mathrm{H}$ kritis oleh tanah dasarnya agar tidak terjadi kelongsoran. Untuk menentukan $\mathrm{H}$ kritis digunakan program bantu GEO 5. Pemberian timbunan secara bertahap dapat dilihat pada Gambar 1.

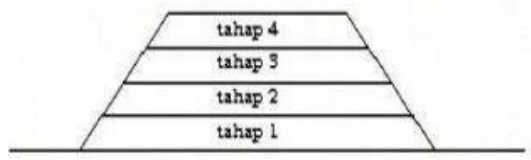

Gambar 1. Pemberian Preloading Secara Bertahap

Metode Percepatan Pemampatan Dengan PVD (Prefabricated Vertical Drain)

PVD berbentuk pita dengan tampang empat persegi panjang dengan lebar $100 \mathrm{~mm}$ dan tebal $4 \mathrm{~mm}$ dan dibuat dari geosintetis yang menyelubungi inti plastik. Selubung luar umumnya dibuat dari geotekstil nir-anyam (non-woven) yang terbuat dari polyester atau polypropylene. Inti plastik berfungsi sebagai 
penahan selubung filter, dan untuk memberikan aliran longitudinal di sepanjang PVD. Inti, umumnya terdiri dari lipatan plastik atau rajutan benang - benang plastik atau material lainnya. Selubung PVD berfungsi sebagai pemisah aliran air terhadap tekanan tanah di sekitarnya, dan merupakan filter agar butiran halus tidak masuk ke dalam luasan inti.

Pola pemasangan Bujur sangkar

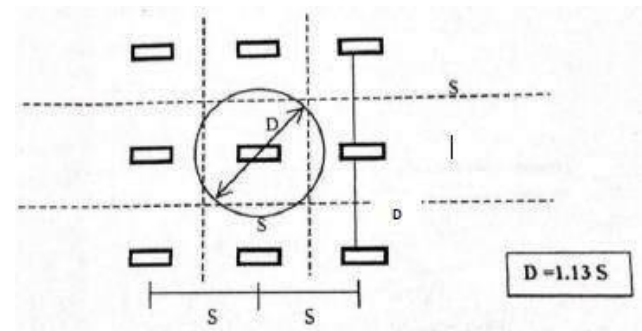

Pola pemasangan Segitiga

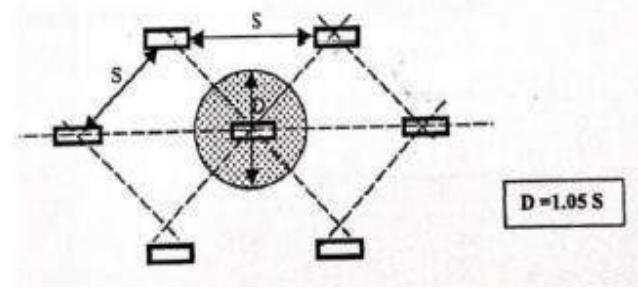

\section{Kenaikan Daya Dukung Tanah}

Sebagai akibatnya terjadinya konsolidasi pada suatu lapisan tanah, maka lapisan tanah yang bersangkutan menjadi lebih padat yang berarti kekuatan tanah juga meningkat sebagai akibat kenaikan harga $\mathrm{Cu}$ (undrained shear strength).

Untuk mendapatkan kenaikan daya dukung tanah perlu ditinjau tegangan tanah awal (po') dan juga penambahan tegangan beban. Untuk penambahan tegangan beban digunakan persamaan berikut (dalam $t_{1}$ dan $U_{1}$ ):

$$
\Delta P_{U 1}=\left(\frac{\sigma_{1}^{\prime}}{p_{o_{o}}}\right)^{U 1} \cdot p^{\prime}{ }_{o}-p^{\prime}{ }_{o}
$$

Dengan adanya penambahan beban, tegangan tanah di lapisan yang ditinjau menjadi (dalam $\mathrm{t}_{1}$ dan $\mathrm{U}_{1}$ ):

$$
\sigma_{(\text {baru })}^{\prime}=p_{o}^{\prime}+\left[\left(\frac{\sigma_{1 / 1}}{p_{o}}\right)^{U 1} \cdot p_{o}^{\prime}-p_{o}^{\prime}\right]
$$

Dari pengamatan dan penelitian diketahui adanya hubungan antara kekuatan geser undrained $(\mathrm{Cu}=$ undrained shear strength $)$ dengan tegangan tanah vertikal efektif ( $p^{\prime}$ ') yang bekerja pada tanah yang sedang mengalami konsolidasi, harga p' berubah dengan waktu.
Harga $\sigma_{\text {baru }}$ dipakai untuk mencari $\mathrm{Cu}$ baru sebagai parameter kekuatan daya dukung tanah dasar setelah terjadi konsolidasi selama t waktu.

- Untuk PI $<120 \%$ :

$\mathrm{Cu}\left(\mathrm{kg} / \mathrm{cm}^{2}\right)=0,0737+(0,1899-0,0016 . \mathrm{PI})$. $\sigma \mathrm{p}$ '

- Untuk PI >120\% :

$\mathrm{Cu}\left(\mathrm{kg} / \mathrm{cm}^{2}\right)=0,0737+(0,0454-0,00004$. PI). $\sigma p$ '

Setelah perhitungan peningkatan $\mathrm{Cu}$, kemudian dihitung penurunan yang diakibat timbunan bertahap. Menggunakan persamaan berikut:

- Apabila p' ${ }_{0}+\Delta \mathrm{p} 1 \leq \mathrm{p}_{\mathrm{c}}$

$$
S c=\frac{C_{S} H}{1+e_{0}} \log \left(\frac{p \prime_{0}+\Delta p 1}{p \prime_{0}}\right)
$$

- Apabila p' ${ }_{0}+\Delta \mathrm{p} 1+\Delta \mathrm{p} 2>\mathrm{p}_{\mathrm{c}}$

$S c=\frac{C_{s} H}{1+e_{0}} \log \left(\frac{p^{\prime} c}{p^{\prime}{ }_{c}+\Delta p 1}\right)+\frac{C_{c} H}{1+e_{0}} \log \left(\frac{p_{0}+\Delta p 1+\Delta p 2}{p_{c}}\right)$

- Apabila $\mathrm{p}_{0}+\Delta \mathrm{p} 1+\Delta \mathrm{p} 2+\Delta \mathrm{p} 3>\mathrm{p}_{\mathrm{c}}$

$S c=\frac{C_{c} H}{1+e_{0}} \log \left(\frac{p \prime_{0}+\Delta p 1+\Delta p 2+\Delta p 3}{p \prime_{0}+\Delta p 1+\Delta p 2}\right)$

\section{METODOLOGIPENELITIAN}

\section{Lokasi Proyek}

Lokasi proyek jalan tol secara administrasi berada di pada dua Kabupaten yakni Kabupaten pasuruan dan Kabupaten Probolinggo Jawa Timur sepanjang $31,2 \quad \mathrm{Km}$ yang menghubungkan Pasuruan dengan Probolinggo. Untuk lokasi pembahasan studi kasus terdapat pada section 2 (seksi 2) yang secara administrasi berada di Kabupaten Probolinggo.
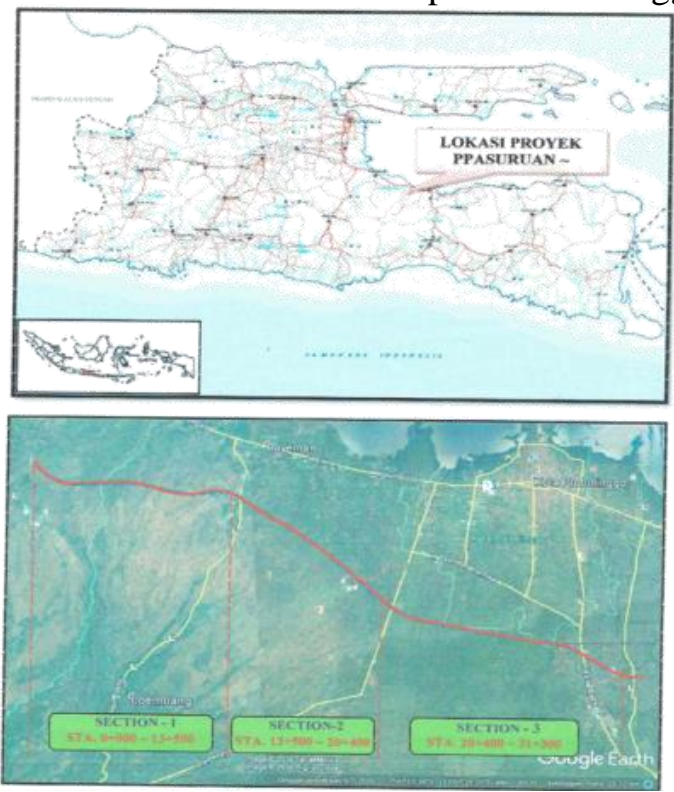


\section{Flow chart}

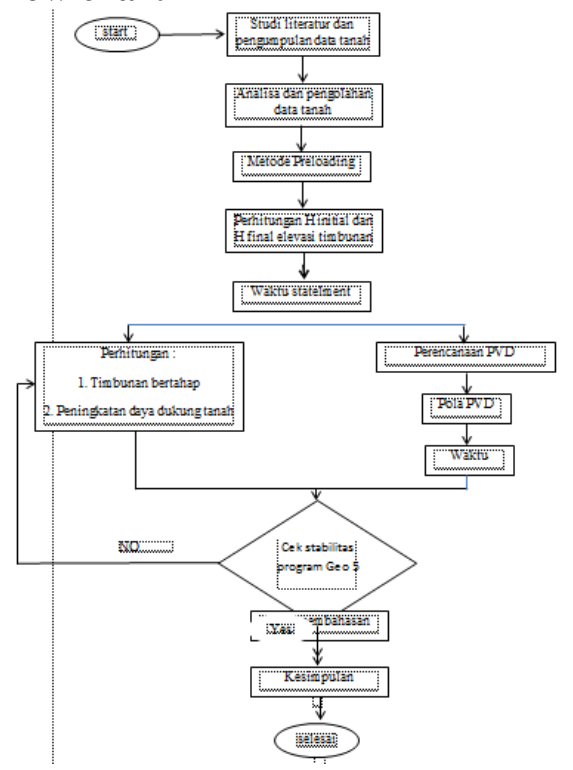

\section{Hipotesis}

H1. Hipotesis Stabilitas tanah dasar di bawah embankment (timbunan)

$\mathrm{HO}$ : ada kelongsoran pada tanah dasar

Ha : tidak ada kelongsoran pada tanah dasar $\mathrm{H} 2$. Hipotesis perbaikan tanah dasar di bawah embankment (timbunan)

$\mathrm{H} 0$ : ada perbaikan daya dukung tanah dasar

Ha : tidak ada perbaiakan daya dukung tanah dasar

H3. Hipotesis penggunaan metode preloading dan PVD

H0 : ada percepatan kenaikan daya dukung tanah setelah perbaikan

Ha : tidak ada percepatan setelah perbaikan tanah dasar

\section{ANALISA DAN PEMBAHASAN}

Data Tanah Dasar

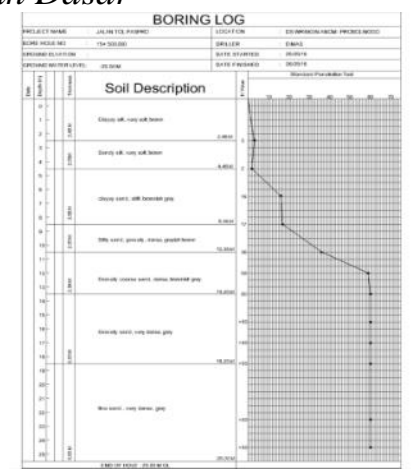

Gambar 2. Data Boring Log (STA 15+500)
Tabel 1. Hasil Data Bore Log

\begin{tabular}{|c|c|c|c|c|c|}
\hline \multicolumn{2}{|c|}{ KEDALAMAN (M) } & RATA-RATA NILAI N-SPT & & \multicolumn{2}{c|}{ KONSISTENSI TANAH MENURUT TABEL 2.1 } \\
\hline & (m) & & & \\
\hline H1 & 4.48 & 2.5 & SANGAT LUNAK (VERY SOFT) & \\
\hline H2 & 5.88 & 17.8 & LUNAK & \\
\hline H3 & 14.64 & 57.5 & KERAS (HARD) & \\
\hline
\end{tabular}

Tabel 2. Harga Parameter Tanah dasar

\begin{tabular}{|c|c|c|c|c|c|c|c|c|c|c|c|c|c|c|c|c|c|c|}
\hline mittin & & N.5T & $\begin{array}{ll}y \\
m y=1\end{array}$ & 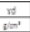 & $\therefore$ & $n$ & W:trot & vat & $\frac{1}{c_{0 n}}$ & $\frac{\theta}{\sigma^{2} h}$ & 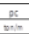 & $\sigma^{6+20}$ & 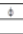 & $\frac{\omega}{k N m^{3}}$ & 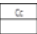 & \& & & \begin{tabular}{|l|l|}
$t m^{3}$ \\
$m^{2}$
\end{tabular} \\
\hline$\theta_{i x} x$ & rit & 25 & 15 & 08 & 28 & or & 48 & 15 & & 00002 & 5200 & $D$ & B & 150 & oess & O128\% & $n$ & 32 \\
\hline & 12 & 128 & is & 10 & 17 & 0.8 & $\Leftrightarrow$ & is & $210^{*}$ & 00005 & 2,30 & 0.5 & 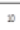 & | & 0286 & othe & 33 & 78 \\
\hline sosing & 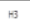 & 575 & 20 & 25 & $20 x$ & 0.004 & 26 & 151 & & & 314 & 0.01 & $D$ & 1400 & 10050 & 168680 & 37 & 8.4 \\
\hline
\end{tabular}

\section{Data Tanah Timbunan}

Material timbunan jalan yang digunakan berasal dari quarry di dekat proyek jalan tol tersebut. Spesifikasi teknis dari material adalah sebagai berikut:

Tabel 3. Data Tanah Timbunan

\begin{tabular}{|c|c|c|c|c|c|c|}
\hline $\mathrm{Cu}\left(\mathrm{Kn} / \mathrm{m}^{2}\right)$ & $\gamma_{\text {sat }}\left(\mathrm{t} / \mathrm{m}^{3}\right)$ & $\gamma_{\mathrm{t}}\left(\mathrm{t} / \mathrm{m}^{3}\right)$ & LL (\%) & PL (\%) & PI (\%) & OMC(\%) \\
\hline 82.7 & 1.34 & 1.6 & 48.05 & 37.48 & 10.57 & 34.55 \\
\hline
\end{tabular}

\section{Geometri Timbunan}

Data-data perencanaan dari geometri timbunan adala sebagai berikut:

- $\quad$ Tinggi timbunan hingga $8.5 \mathrm{~m}$.

- Lebar atas timbunan $27.2 \mathrm{~m}$.

- Kemiringan timbunan 2:1.

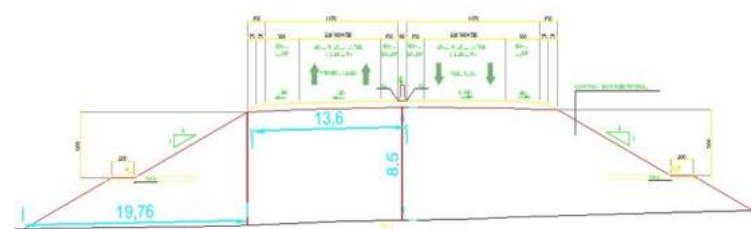

\section{Analisa Beban Di Atas Embankmnet (Timbunan)}

Beban Perkerasan

Berikut ini adalah analisa beban perkerasan terhadap timbunan jenis perkerasan yang di pakai adalah perkerasan kaku.

\begin{tabular}{|c|c|c|c|c|}
\hline no & Jenis perkerasan & Tebal $(\mathrm{m})$ & Berat jenis $t \mathrm{~m}^{3}$ & Berat perkerasan $\mathrm{t} \mathrm{m}^{2}$ \\
\hline 1 & RIGID & 0.31 & 2.2 & 0.682 \\
\hline 2 & LC & 0.11 & 2.2 & 0.242 \\
\hline 3 & LPA & 0.12 & 1.8 & 0.216 \\
\hline & & & TOTAL & $1.14 \mathrm{t} / \mathrm{m}^{2}$ \\
\hline
\end{tabular}

Dengan total tebal perkerasan $0.54 \mathrm{~m}$ maka $\mathrm{q}$ total perkerasan adalah $1,14 \mathrm{t} / \mathrm{m}^{2}$

\section{Beban Lalulintas}

Untuk beban lalu lintas menggunakan grafik hubungan tinggi timbunan dan beban lalu lintas pada 
Tabel 4. Hubungan Beban Traffic Dan Tinggi Timbunan

\begin{tabular}{|l|c|c|c|c|}
\hline $\begin{array}{l}\text { Tinggi } \\
\text { timbunan (m) }\end{array}$ & 2 & 3 & 4 & 5 \\
\hline $\begin{array}{l}\text { H bongkar } \\
\text { Traffic (m) }\end{array}$ & 1.119 & 0.896 & 0.597 & 0.448 \\
\hline
\end{tabular}

\section{Penambahan Tegangan $(\Delta p)$ Timbunan}

Penambahan tegangan berasal dari beban timbunan, dalam perhitungan ini beban pemisalan timbunan yang dipakai adalah $\mathrm{q}=5$ $\mathrm{t} / \mathrm{m}^{2}$. Untuk menghitung $\Delta \mathrm{p}$ meggunakan persamaan, dengan data sebagai berikut.

Lapisan Pertama (H1)

$$
\begin{array}{lr}
a=17 \mathrm{~m} & \mathrm{z}=2.24 \mathrm{~m} \\
\mathrm{~b}=13.6 \mathrm{~m} & \mathrm{a} / \mathrm{z}=7.59 \mathrm{~m} \\
\mathrm{~b} / \mathrm{z}=6.07 \mathrm{~m}
\end{array}
$$

$\mathrm{I}=32$

Menghitung $\Delta \mathrm{p}$ memerlukan nilai I, dan distribusi tegangan pada timbunan dianggap distribusi bentuk trapezium, sedangkan nilai I didapat dari Persamaan grafik NAVFAC dengan distribusi bentuk trapesium yaitu $\mathrm{I}=45$

Penggunaan grafik NAVFAC (gambar 2.2) hanya untuk setengah timbunan, jadi untuk perhitungan timbunan yang utuh nilai I dikalikan 2

$$
\begin{aligned}
\Delta \mathrm{p} & =2 \times \mathrm{q} \times \mathrm{I} \\
& =2 \times 5 \mathrm{t} / \mathrm{m}^{2} \times 32 \\
& =3.2 \mathrm{t} / \mathrm{m}^{2}
\end{aligned}
$$

Tabel 5. Penambahan Tegangan $\Delta \mathrm{p}$ (Timbunan)

\begin{tabular}{|c|c|c|c|}
\hline \multirow{2}{*}{$\Delta \mathrm{P}$} & \multicolumn{3}{|c|}{ lapisan } \\
\cline { 2 - 4 } & $\mathrm{H} 1$ & $\mathrm{H} 2$ & $\mathrm{H} 3$ \\
\hline 5 & 3.2 & 1.3 & 0.7 \\
\hline 7 & 4.48 & 1.82 & 0.98 \\
\hline 9 & 5.76 & 2.34 & 1.26 \\
\hline 12 & 7.68 & 3.12 & 1.68 \\
\hline 18 & 11.52 & 4.68 & 2.52 \\
\hline
\end{tabular}

\section{Pemampatan $(\mathrm{Sc})$}

Untuk menghitung pemampatan harus memperhatikan dari sifat tanah, apakah normally consolidated atau over consolidated. Untuk perhitungan kali ini di tentukan sifat tanah yakni over consolidated untuk sifat tanah over consolidated dengan $\mathrm{Po}^{\prime}+\Delta \mathrm{p} \leq \mathrm{Pc}^{\prime}$, dan persamaan 2.8 untuk sifat tanah over consolidated dengan Po' $+\Delta \mathrm{p}>\mathrm{Pc}^{\prime}$. Pehitungan untuk $\mathrm{q}$ design beban 5 ton $/ \mathrm{m}^{2}$ yang menghasilkan sattlement sebesa $0.74 \mathrm{~m}$ bisa dilihat di tabel 4.8, untuk design beban selanjutnya tedapat pada tabel 4.9.

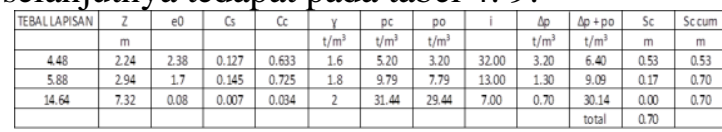

Tabel 6. Hasil Pemampatan Terhadap Beban Design (q)

\begin{tabular}{|c|c|}
\hline $\mathrm{q}$ (beban) & $\mathrm{Sc}$ (sattlement) \\
\hline $\mathrm{t} / \mathrm{m}^{2}$ & $\mathrm{~m}$ \\
\hline 5 & 0.7 \\
\hline 7 & 0.73 \\
\hline 9 & 0.75 \\
\hline 12 & 0.77 \\
\hline 18 & 0.8 \\
\hline
\end{tabular}

\section{Penambahan Tegangan $(\Delta p)$ Perkerasan}

Penambahan tegangan akibat perkerasan menghasilkan pemampatan yang berbeda dari beban timbunan. Jarak lapisan bawah perkerasan ke tanah dasar ditambah dengan tinggi timbunan, dan distribusi tegangan perkerasan menggunakan distribusi tegangan persegi.
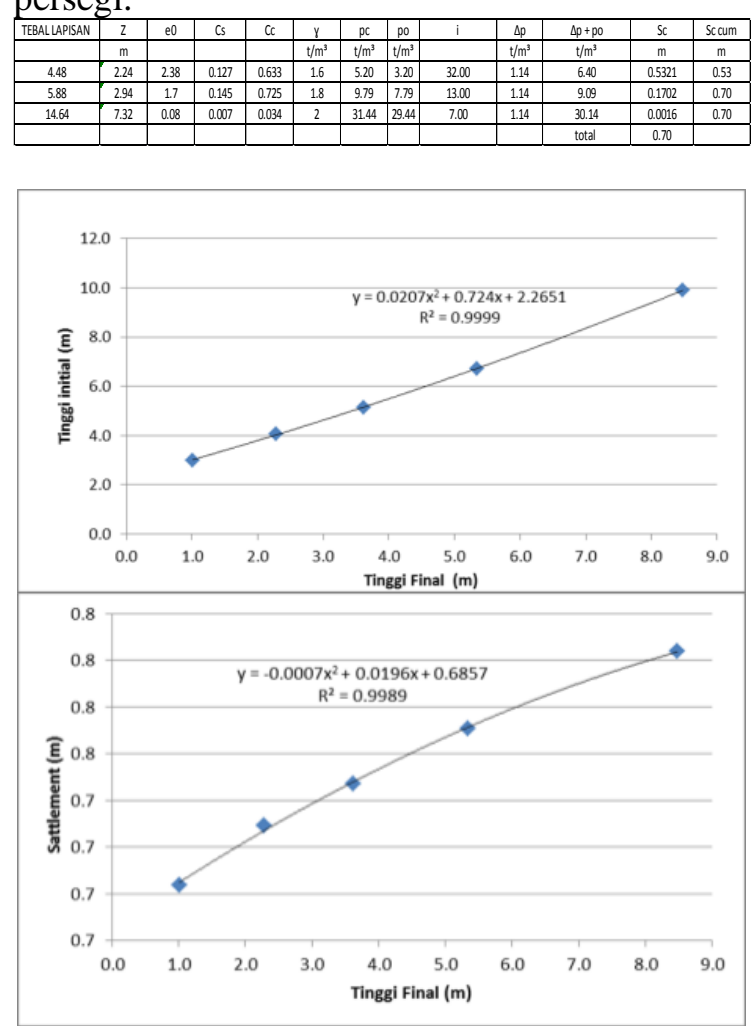

\section{Waktu Pemampatan}

Setelah didapatkan besar pemampatan yang terjadi akibat beban timbunan dan beban surcharge, dilakukan perhitungan waktu 
konsolidasi yang dibutuhkan untuk menyelesaikan pemampatan tersebut menggunakan Persamaan 2.8. Hal ini dilakukan untuk menentukan perlu atau tidaknya perbaikan tanah dasar untuk mempercepat waktu pemampatan yang terjadi

$$
\begin{aligned}
& \mathrm{T}=90 \% \\
& \mathrm{Hdr}=10.36 \mathrm{~m} \\
& \mathrm{Cv}=0.014112 \mathrm{~m}^{2} / \mathrm{minggu} \\
& \mathrm{t}=\mathrm{T} 90 \% \times(\mathrm{Hdr})^{2} / \mathrm{Cv} \text { rata-rata } \\
& \mathrm{t}=48 \text { Tahun }
\end{aligned}
$$

\section{Penurunan Tanah Tanpa PVD}

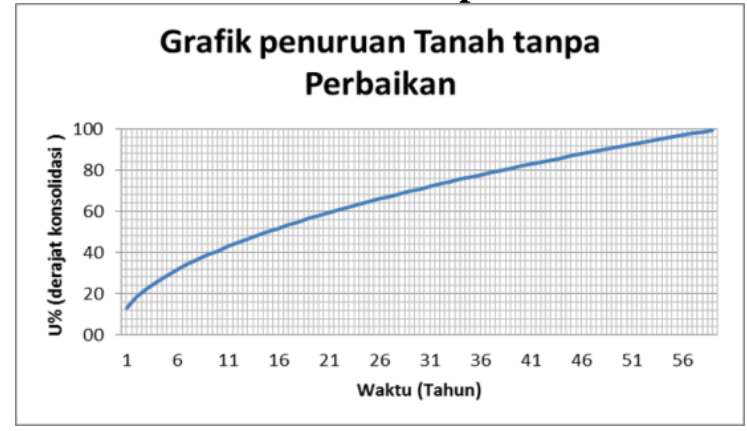

\section{Perhitungan Derajat Konsolidasi}

\section{Vertikal (Uv)}

Dalam hal ini besarnya $U_{v}$ diasumsikan kurang dari $60 \%$ sehingga digunakan Persamaan 2-11.Berdasarkan persamaan, untuk menghitung nilai Uv membutuhkan faktor nilai Tv. Nilai $\mathrm{Tv}$ dapat dihitung menggunakan Persamaan 2-23, dan dalam perencanaan ini $t$ (waktu) dibuat dalam satuan minggu

Tabel 7. Perhitungan Tv

\begin{tabular}{|c|c|}
\hline T (minggu) & Tv \\
\hline 0.5 & $8.99719 \mathrm{E}-05$ \\
\hline 1 & 0.000179944 \\
\hline 2 & 0.000359888 \\
\hline 3 & 0.000539832 \\
\hline 4 & 0.000719776 \\
\hline 5 & 0.000899719 \\
\hline 6 & 0.001079663 \\
\hline 7 & 0.001259607 \\
\hline 8 & 0.001439551 \\
\hline 9 & 0.001619495 \\
\hline 10 & 0.001799439 \\
\hline
\end{tabular}

Tabel 7. Perhitungan Uv

\begin{tabular}{|c|c|}
\hline $\mathrm{T}$ (minggu) & UV \\
\hline 0.5 & 0.01070579 \\
\hline 1 & 0.015140274 \\
\hline 2 & 0.02141158 \\
\hline 3 & 0.026223723 \\
\hline 4 & 0.030280547 \\
\hline 5 & 0.033854681 \\
\hline 6 & 0.037085945 \\
\hline 7 & 0.040057399 \\
\hline 8 & 0.042823161 \\
\hline 9 & 0.045420821 \\
\hline 10 & 0.047878 \\
\hline
\end{tabular}

\section{Derajat Konsolidasi Horizontal}

Derajat konsolidasi horizontal diperoleh dari Persamaan 2-25. Dalam perhitungan Uh dibutuhkan beberapa parameter seperti $\mathrm{F}(\mathrm{n})$, $\mathrm{Ch}$, dan D. Untuk parameter $\mathrm{Ch}$ dibutuhkan perbandingan parameter koefisien permeabilitas horisontal (Kh)dan koefisien permeabilitas vertikal $(\mathrm{Kv})$, namun hal tersebut harus berdasarkan penelitian. Jadi dalam perencanaan iniperbandingan $\mathrm{Kh}$ dan $\mathrm{Kv}$ berdasarkan perkiraan interval 2 - 5.Perhitungan berikut menggunakan pola pemasangan segitiga dan bujur sangkardengan spasi $1 \mathrm{~m}$.

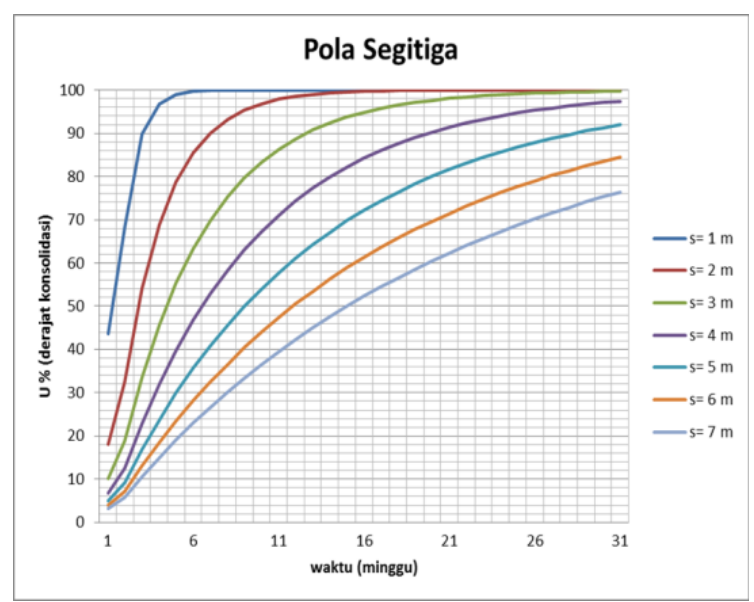




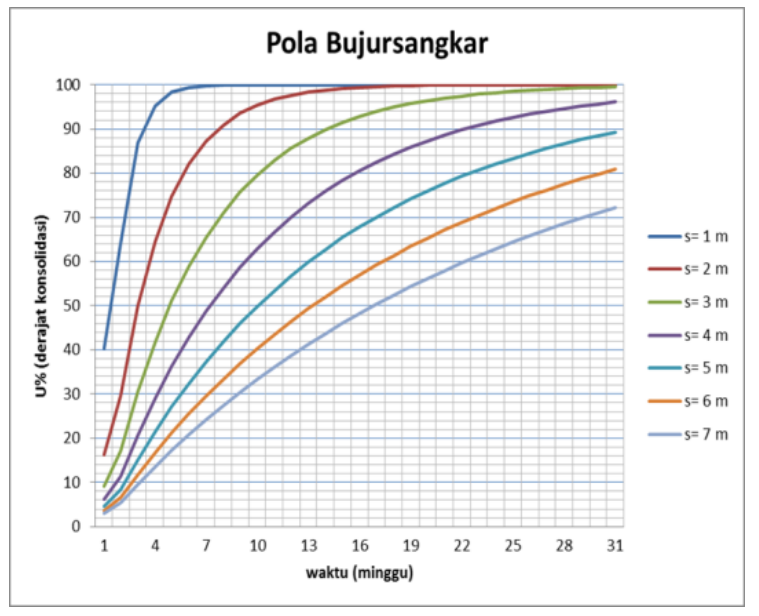

\section{Perhitungan Tinggi $\mathrm{H}$ Kritis}

Pehitungan Tinggi $\mathrm{H}$ kritis di fungsikan untuk melihat stabilitas atau kemampuan tanah dasar untuk menerima beban dari timbunan agar tidak tejadi kelongsoran saat tahap penimbunan di laksanakan, untuk perhitungan ini di gunakan software program GEO 5, yang dapat di lihat pada gambar 4.12 berikut:

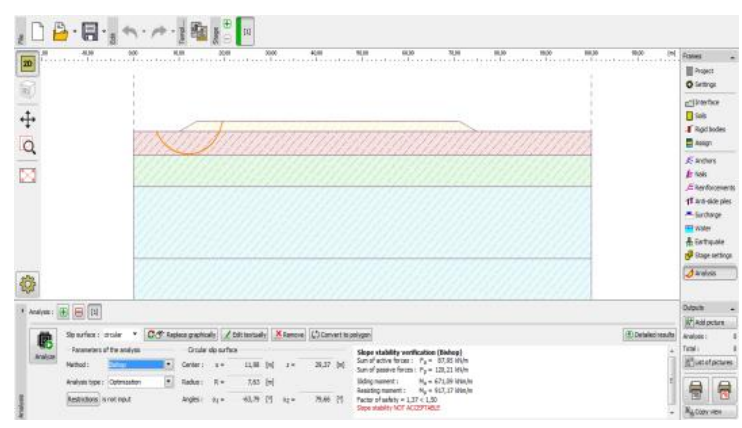

Pada gambar 4.10 di lakukan percobaan timbunan dengan ketinggian Timbunan 2 meter dengan nilai $\mathrm{Cu}$ tanah yang lama didapatkan $\mathrm{SF}$ sebesar 1,37 lebih kecil dari SF keamanan sebesar 1,50 yang berarti pada timbunan tersebut terjadi kelongsoran, dan perlu di design lagi tinggi timbunan agar tidak terjadi longsor, di dapatkan SF yang aman sebesar 1,73 dengan tinggi timbunan 1,5 meter. berarti di tentukan pada tahap awal penimbunan sebagai upaya menaikan $\mathrm{Cu}$ adalah dengan penimbunan bertahap setinggi sampai dengan 1,5 meter

\section{Tahapan Penimbunan}

Pada perencanaan tinggi timbunan kritis di dapat design timbunan setinggi 1,5 meter, untuk itu perlu juga perencanaan tahapan penimbunan supaya usaha peningkatan nilai $\mathrm{Cu}$ tanah dapat tercapai, untuk tahapan penimbunan dilihat pada tabel 4.21.

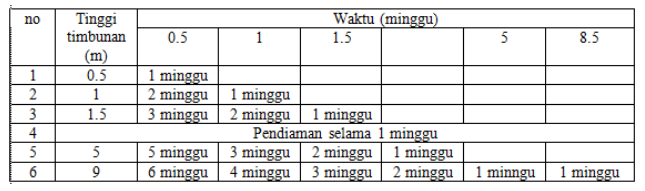

\section{Perhitungan Daya Dukung Tanah}

Dimisalkan pemasangan PVD dengan Jarak $1 \mathrm{~m}$. Dapat dilihat di grafik Pola PVD (gambar 4.7 dan 4.8) hubungan antara U (derajat kejenuhan) dengan $\mathrm{t}$ (Waktu) dimana Pola PVD berpengaruh pada kecepatan kenaikan U derajat atau derajat konsolidasi dimana semakin rapat jarak pemasangan antara PVD makan kenaikan U / derajat konsolidasi juga semakin besar, karena kerapatan PVD makan juga akan mempecepat pengeluaran Air yang berada di dalam lapisan tanah yang terkonsolidasi.

\section{Kenaikan Cu Pola Pemasangan Segitiga}

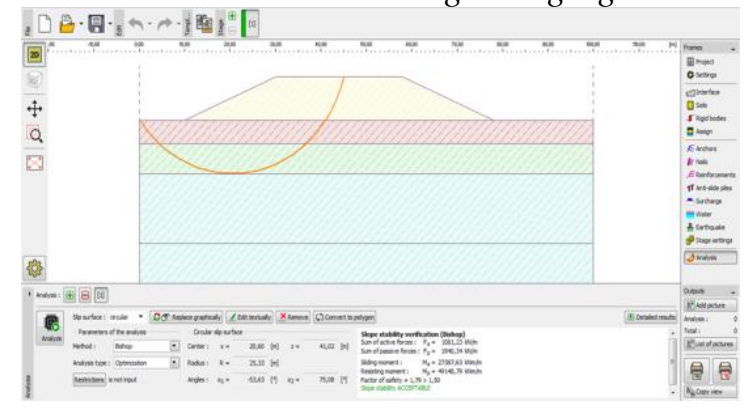

Kenaikan Cu pola pemasangan bujur sangkar

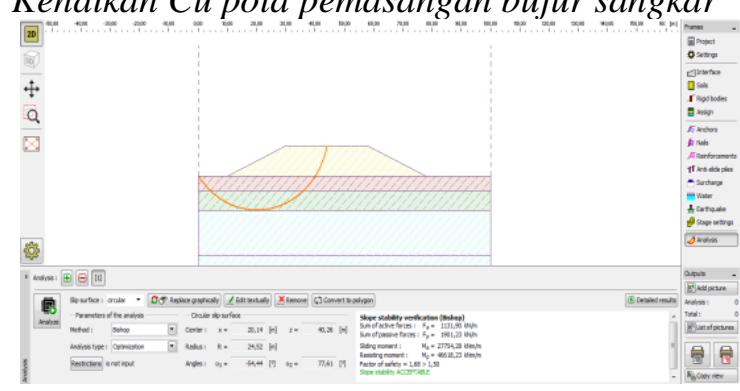

\section{KESIMPULAN DAN SARAN}

\section{Kesimpulan}

1. Lapisan Tanah Dasar pada STA $15+500$ memiliki daya dukung yang rendah dilihat pada hasil Geo 5 hanya mampu 
menerima beban timbunan setinggi 1.5

meter

2. Di perlukan tinggi timbunan initial setinggi 9.90 meter untuk mencapai tinggi rencana 8.5 meter

3. PVD direncanakan dengan menggunakan pola Segitiga dan bujur sangkar dengan jarak 1 meter dengan waktu pengerjaan sampai dengan $\mathrm{H}$ final dapat di kerjakan selama 6 minggu.

4. Preloading di laksanakan secara bertahap selama 6 minngu agar dapat memaksimalkan pemampatan sesuai dengan naiknya derajat konsolidasi yang semula $\mathrm{Cu}$ tanah dasar hanya mampu menahan beban timbunan setinggi 5 meter dengan kombinasi pemasangan PVD dengan pola segitiga dan bujur sangkar jarak 1meter dan penambahan beban tegangan (preloading) secara bertahap maka di dapatkan kenaikan derajat konsolidasi rata-rata sebesar $98 \%$ yang mengakibatkan tanah dasar mampu menahan beban setinggi 9 meter.

\section{Saran}

Perlunya kelengkapan data tanah baik laboratorium maupun test lapangan sebagai penunjang perhitungan yang lebih mendetail lagi untuk hasil yang maksimal serta mudah dalam hal pengontrolan dari hasil tersebut.

\section{DAFTAR PUSTAKA}

Das, Braja M. 1985. Mekanika Tanah (PrinsipPrinsip Rekayasa Geoteknis) Jilid 1, Jakarta: Erlangga.

Das, Braja M. 1985. Mekanika Tanah (PrinsipPrinsip Rekayasa Geoteknis) Jilid 2. Jakarta: Erlangga.

Herman Bahan Ajar - Mekanika Tanah II.

Mochtar, Indrasurya B. Teknologi Perbaikan Tanah Masa Kini.

Wahyudi, Herman. Daya Dukung Pondasi Dangkal. 